\title{
Primary Prevention of Cardiovascular Disease and Type 2 Diabetes Mellitus Using Mobile Health Technology: Systematic Review of the Literature
}

Vera Helen Buss ${ }^{1,2}$, PharmB, RPh, MRes; Stuart Leesong ${ }^{1}$; Margo Barr ${ }^{1}$, BSc, MPH, GCertTertTLP, PhD; Marlien Varnfield $^{2}$, BSc, MSc, PhD; Mark Harris ${ }^{1}$, MBBSMD, DRACOG, FRACGP, PhD

${ }^{1}$ Centre for Primary Health Care and Equity, University of New South Wales, Sydney, Australia

${ }^{2}$ Australian e-Health Research Centre, CSIRO, Brisbane, Australia

\section{Corresponding Author:}

Vera Helen Buss, PharmB, RPh, MRes

Centre for Primary Health Care and Equity

University of New South Wales

Level 3, AGSM Building

UNSW Sydney

Sydney, 2052

Australia

Phone: 61293851547

Email: v.buss@student.unsw.edu.au

\section{Abstract}

Background: Digital technology is an opportunity for public health interventions to reach a large part of the population.

Objective: This systematic literature review aimed to assess the effectiveness of mobile health-based interventions in reducing the risk of cardiovascular disease and type 2 diabetes mellitus.

Methods: We conducted the systematic search in 7 electronic databases using a predefined search strategy. We included articles published between inception of the databases and March 2019 if they reported on the effectiveness of an intervention for prevention of cardiovascular disease or type 2 diabetes via mobile technology. One researcher performed the search, study selection, data extraction, and methodological quality assessment. The steps were validated by the other members of the research team

Results: The search yielded 941 articles for cardiovascular disease, of which 3 met the inclusion criteria, and 732 for type 2 diabetes, of which 6 met the inclusion criteria. The methodological quality of the studies was low, with the main issue being nonblinding of participants. Of the selected studies, 4 used SMS text messaging, 1 used WhatsApp, and the remaining ones used specific smartphone apps. Weight loss and reduction in BMI were the most reported successful outcomes (reported in 4 studies).

Conclusions: Evidence on the effectiveness of mobile health-based interventions in reducing the risk for cardiovascular disease and type 2 diabetes is low due to the quality of the studies and the small effects that were measured. This highlights the need for further high-quality research to investigate the potential of mobile health interventions.

Trial Registration: International Prospective Register of Systematic Reviews (PROSPERO) CRD42019135405; https://www.crd.york.ac.uk/PROSPERO/display_record.php?RecordID=135405

(J Med Internet Res 2020;22(10):e21159) doi: 10.2196/21159

\section{KEYWORDS}

systematic review; mobile health; telemedicine; primary prevention; cardiovascular diseases; diabetes mellitus, type 2

\section{Introduction}

\section{Description of the Condition}

Worldwide, chronic diseases are the main cause of death and years lived with disability [1,2]. Cardiovascular disease (CVD) and type 2 diabetes mellitus (T2DM) are globally among the top 5 chronic conditions in terms of incidence and prevalence [2]. The behavioral risk factors for these conditions, such as smoking, harmful use of alcohol, poor diet, and physical inactivity, are highly correlated with the disease progression [3]. For example, Gellert et al [4] observed in their meta-analysis 
a dose-response relationship between the number of cigarettes smoked and premature death. They also found an inverse correlation between time since cessation and all-cause mortality. Wood et al [5] reported that all-cause mortality was positively associated with the level of alcohol intake, based on data from over half a million current drinkers. Chudasama et al [6] found a negative dose-response relationship between physical activity levels and all-cause mortality in their analysis of almost half a million people. Regarding low whole-grain intake, which is the highest risk factor related to poor diet, in their meta-analysis, Zhang et al [7] showed an inverse dose-response relationship between whole-grain intake and all-cause mortality. Hence, targeting these with preventive measures could significantly reduce people's chronic disease risk [8], and behavior change interventions are well suited for preventing CVD and T2DM $[2,3]$.

\section{Description of the Intervention}

To stop noncommunicable diseases from rising further, the World Health Organization (WHO) developed the Global Action Plan 2013-2020 [8]. In this report, the WHO emphasized the importance of early screening and the implementation of preventive programs. Further, the WHO recommended the use of information and communication technologies, such as the internet and mobile phone technologies, to deliver health education and promotion programs. In 2019, the WHO released a guideline with recommendations on digital interventions for health system strengthening [9]. This report outlined how the implementation of technology could overcome current challenges in health care systems and help to achieve the goal of universal health coverage. Health apps have promising potential. Wilson [10] pointed out that digital health interventions have the advantage of being easily accessible and cost-effective. According to the Pew Research Center [11], many people use their smartphones daily. Riley et al [12] reported that new advancements allow apps to be tailored to personal needs and preferences, as well as the integration of dynamic feedback systems. Despite the promising potential of health apps, there is still ambiguity about their effectiveness, as outlined by the WHO guideline [9].

\section{Objective}

The aim of this systematic literature review was to assess the current evidence regarding the effectiveness of mobile health-based interventions in reducing the risk for CVD and T2DM. The focus was on multiple behavioral risk-factor interventions, rather than single risk-factor interventions, because of the lack of evidence on their combined effectiveness compared with substantial evidence on single risk-factor interventions $[13,14]$.

\section{Methods}

\section{Review Standards}

We conducted this systematic review in accordance with the Preferred Reporting Items for Systematic Reviews and Meta-Analyses (PRISMA) statement [15] and registered it with International Prospective Register of Systematic Reviews (PROSPERO; registration number CRD42019135405).

\section{Search Strategy}

We searched the following medical and bioengineering databases to retrieve all relevant articles regarding preventive mobile health intervention for CVD and T2DM: EMBASE (via Ovid), Scopus, ScienceDirect, CINAHL (via EBSCOhost), MEDLINE (via Ovid), ProQuest science and technology databases, and Ei Compendex and Inspec (both via Engineering Village 2). The search strategy (Multimedia Appendix 1) included terms relating to the 2 conditions under study and the intervention; we combined the terms using Boolean operators [16] and adapted the terms to the database-specific requirements. The search included articles published from the inception of the databases until March 25, 2019. We limited the search to English- and German-language publications because these languages were proficiently spoken by the review team. We excluded review articles, conference abstracts, comments, editorials, letters to the editor, and theses. Additionally, we identified studies using "snowballing" techniques by reviewing the reference lists of articles included in the initial search and searching for other publications by authors included in the initial search [17].

\section{Study Selection}

\section{Inclusion Criteria}

The study selection followed predefined inclusion criteria according to the PICOS system (Table 1). After removing duplicate publications, we reviewed all retrieved articles for eligibility, first by examining the titles and abstracts, and then the full articles if we considered the articles to be relevant in the first step. We included in the review full articles that met the inclusion and exclusion criteria. The steps described above were performed by 1 researcher (VHB). For the title and abstract screening, a $10 \%$ random sample of all retrieved articles was validated by a second researcher (shared between the remaining researchers). If discrepancies occurred, a third researcher resolved the issue. A second researcher (SL) independently assessed which of the full articles fulfilled the inclusion and exclusion criteria. The results were compared, and discrepancies were resolved by involving a third researcher (MB). 
Table 1. Inclusion criteria according to the PICOS system.

\begin{tabular}{|c|c|}
\hline Criteria & Description of inclusion criteria \\
\hline Participants & Adults who are free of $\mathrm{CVD}^{\mathrm{a}}$ or $\mathrm{T}_{2} \mathrm{DM}^{\mathrm{b}}$. \\
\hline Intervention & $\begin{array}{l}\text { Health promotion interventions that use mobile health technology (ie, mobile app or SMS } \\
\text { text messaging) aiming to change more than } 1 \text { risk factor for } 1 \text { of the } 2 \text { chronic conditions } \\
\text { under study. }\end{array}$ \\
\hline Comparator & No intervention (ie, standard care), or waitlist control, or intervention delivered in person. \\
\hline Outcome & $\begin{array}{l}\text { Onset of disease (CVD or T2DM) or relative risk reduction, which can be in the form of } \\
\text { surrogate parameters. }\end{array}$ \\
\hline Study design & Randomized controlled trial, case-control study, or interrupted time series. \\
\hline
\end{tabular}

${ }^{\mathrm{a}} \mathrm{CVD}$ : cardiovascular disease.

${ }^{\mathrm{b}}$ T2DM: type 2 diabetes mellitus.

\section{Types of Participants}

Participants could either be healthy or have an increased disease risk. We excluded interventions targeting adults who were already diagnosed with CVD or T2DM (depending on the aim of the intervention, eg, for CVD prevention, people diagnosed with CVD) at baseline. Further, we excluded studies intended for minors ( $<18$ years of age). The conditions under study were CVD and T2DM, for which we applied the following WHO definitions: CVD is a "group of disorders of heart and blood vessels," including coronary heart disease, cerebrovascular disease, peripheral vascular disease, heart failure, rheumatic heart disease, congenital heart disease, and cardiomyopathies [18]; T2DM "is a chronic disease that occurs...when the body cannot effectively use the insulin it produces" [19].

\section{Types of Intervention}

We included primary studies if they evaluated the effectiveness of a mobile phone-based intervention for primary prevention of 1 of the conditions under study. The intervention had to be delivered, at least partially, via mobile health technology (ie, mobile app or SMS text messaging) with the aim of changing more than 1 risk factor for 1 or more of the chronic conditions under study. We defined a mobile app as a software program that can run on mobile devices such as smartphones, and a text message as a written message sent to a mobile phone. The type of interventions that we included needed to be aimed at health promotion using behavior change strategies, including counselling or education regarding disease-related knowledge, healthy diet, physical activity, smoking cessation, motivational messages, and goal setting. We excluded from the review studies that exclusively targeted 1 behavioral risk factor (eg, smoking only, diet only, or step count only).

\section{Types of Comparator}

The comparison group could consist of either no intervention (ie, standard care), or a waitlist control, or an intervention delivered in person. Studies were eligible if they included adults who were free of CVD or T2DM at study baseline, depending on the condition targeted in the study.

\section{Types of Outcome}

Studies were only eligible for inclusion if their main outcomes were disease incidence (either CVD or T2DM) or a reduction in disease risk, which could be measured using a risk prediction tool (such as the Framingham score for CVD [20]) or surrogate parameters. Examples of surrogate parameters were weight, waist circumference, blood pressure, blood glucose, level of physical activity, dietary intake, or smoking status. Additional outcomes that we included in the review were the feasibility of mobile health interventions, disease knowledge, and quality of life. Respective outcome measures included dropout rates, participants' acceptability of and adherence to the intervention, and questionnaires assessing disease knowledge and quality of life.

\section{Types of Study Design}

We restricted the study design to randomized controlled trials (RCTs), case-control studies, and interrupted time series in order to have a measurement against which the effectiveness of the intervention could be compared.

\section{Data Extraction and Synthesis}

Relevant data (study objective, study design, study population, comparator, description of the intervention, duration of the intervention or follow-up, outcomes, main results, and methodology for the assessment of the study's quality) were extracted by 1 researcher (VHB) using a standardized form in Excel 365 (Microsoft Corporation). This was reviewed by all the other researchers. We synthesized the main results of the included studies in a narrative manner focusing on the intervention delivery and reported outcomes. A meta-analysis was not possible due to the small number of identified studies and the heterogeneity in interventions and outcomes.

\section{Literature Quality Assessment}

One researcher (VHB) assessed the risk of bias using the following assessment tools: for RCTs, the Cochrane Collaboration's tool for assessing risk of bias [21]; and for non-RCTs, the Risk of Bias In Non-randomized Studies - of Intervention assessment tool [22].

\section{Results}

Results of the Literature Search and Study Selection

In total, we identified 941 articles using the search strategy for CVD and 732 articles using the search strategy for T2DM. In the validation of the $10 \%$ random sample of all retrieved articles, 
there was a $100 \%$ agreement (after initial disagreements were resolved by a third investigator) with the selection conducted by the researcher who screened all articles. Finally, 3 CVD articles [23-25] and 6 T2DM articles [26-31] fulfilled the inclusion and exclusion criteria; we identified no additional articles through the snowballing technique (Figures 1 and 2). We excluded many articles for several of the exclusion criteria.

Figure 1. Full article selection process for cardiovascular disease.

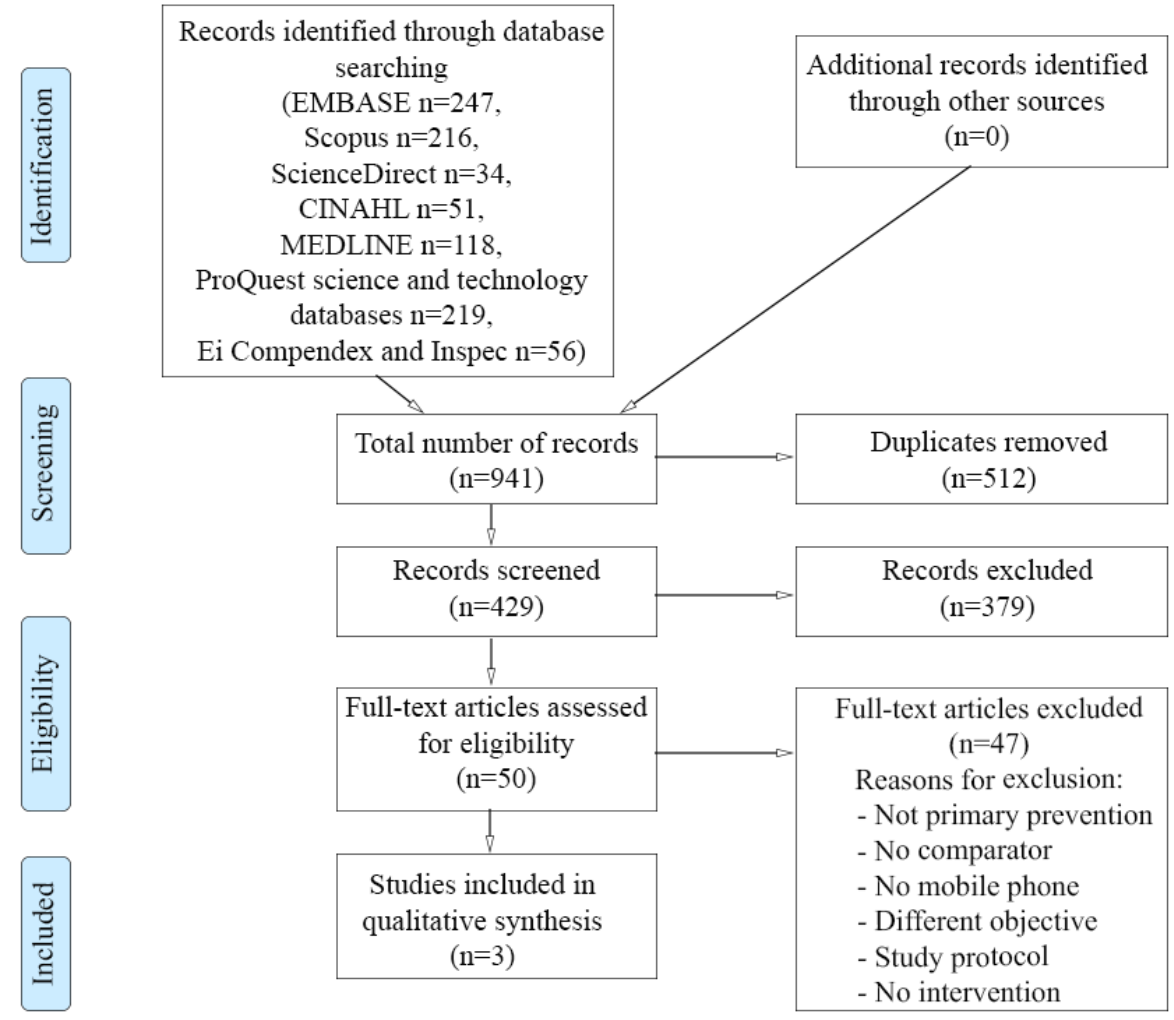

Figure 2. Full article selection process for type 2 diabetes.

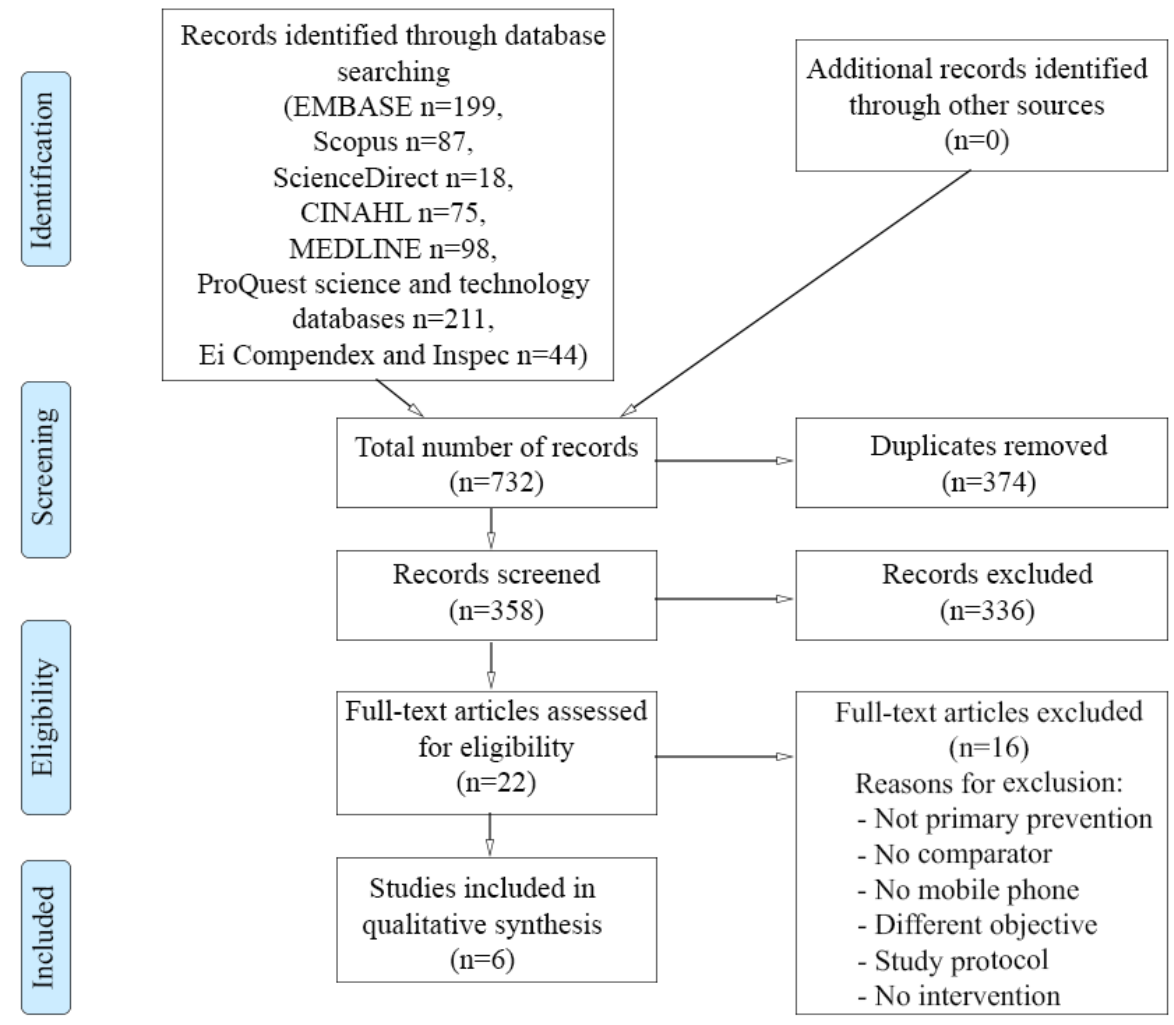




\section{Results of the Data Extraction}

There were 3 CVD [23-25] and 6 T2DM studies [26-31]. Table 2 provides details about the CVD studies and Table 3 provides details about the T2DM studies. For each study, the table includes the first author, year of publication, study design and duration, objectives, study population, interventions and comparators, outcomes, and the main results.

Table 2. Data extraction from cardiovascular disease (CVD) studies.

\begin{tabular}{|c|c|c|c|c|c|}
\hline $\begin{array}{l}\text { First author, } \\
\text { date, reference }\end{array}$ & $\begin{array}{l}\text { Study design and } \\
\text { duration; objec- } \\
\text { tives }\end{array}$ & Study population & Intervention and comparator & Outcomes & Main results \\
\hline Gore, 2019 [23] & $\begin{array}{l}\text { Non-RCT }{ }^{\mathrm{a}} \text { for } 12 \\
\text { months; effective- } \\
\text { ness of an SMS } \\
\text { text message inter- } \\
\text { vention to reduce } \\
\text { CVD risk }\end{array}$ & $\begin{array}{l}\text { Adults from the United } \\
\text { States at high risk of } \\
\text { CVD without preexist- } \\
\text { ing coronary artery dis- } \\
\text { ease, cerebrovascular } \\
\text { disease, and diabetes; } \\
\text { intervention } n=204 \text {, } \\
\text { usual care } n=408\end{array}$ & $\begin{array}{l}\text { Create action plan with } \\
\text { community health workers } \\
\text { and return } 6-12 \text { months after } \\
\text { initial screening for retest- } \\
\text { ing; intervention: text mes- } \\
\text { sages once/day on advice on } \\
\text { healthy eating, } \text { PA }^{\mathrm{b}} \text {, weight } \\
\text { loss, contacting community } \\
\text { health worker; control: usual } \\
\text { care }\end{array}$ & $\begin{array}{l}\text { Engagement, pro- } \\
\text { gram retention, } \\
\text { changes in risk } \\
\text { factors (smoking, } \\
\text { fat and fiber intake, } \\
\text { PA, weight, BMI, } \\
\mathrm{BP}^{\mathrm{c}} \text {, low-density } \\
\text { lipoprotein), Fram- } \\
\text { ingham risk score }\end{array}$ & $\begin{array}{l}\text { Only statistically significant de- } \\
\text { crease in fat intake (intervention } \\
-26.3 \% \text { vs control }-10.6 \% \text {; } \\
P=.001)\end{array}$ \\
\hline $\begin{array}{l}\text { Muntaner-Mas, } \\
2017 \text { [24] }\end{array}$ & $\begin{array}{l}\text { Non-RCT for } 10 \\
\text { weeks; effective- } \\
\text { ness of a What- } \\
\text { sApp-based PA in- } \\
\text { tervention to re- } \\
\text { duce CVD risk } \\
\text { factors }\end{array}$ & $\begin{array}{l}\text { Spanish adults aged 53- } \\
73 \text { years without medi- } \\
\text { cal conditions or other } \\
\text { physical problems re- } \\
\text { quiring special medical } \\
\text { attention and who were } \\
\text { able to perform rigor- } \\
\text { ous PA; mobile group } \\
n=7 \text {, training group } \\
n=16 \text {, control } n=9\end{array}$ & $\begin{array}{l}\text { Intervention: twice/week } \\
\text { functional fitness for train- } \\
\text { ing and mobile group; for } \\
\text { training group face-to-face } \\
\text { sessions, for mobile group } \\
\text { training videos for download } \\
\text { via WhatsApp, chat function } \\
\text { plus motivational messages } \\
\text { from study coordinator; } \\
\text { control: no intervention }\end{array}$ & $\begin{array}{l}\mathrm{BP}, \mathrm{WC}^{\mathrm{d}} \text {, waist to } \\
\text { height ratio, } \\
\text { weight, BMI, fat } \\
\text { mass index, fat- } \\
\text { free mass index, } \\
\text { heart rate after exer- } \\
\text { cise, balance, } \\
\text { handgrip strength, } \\
\text { aerobic capacity }\end{array}$ & $\begin{array}{l}\text { No statistically significant differ- } \\
\text { ences between mobile group and } \\
\text { control; statistically significant } \\
\text { differences between training } \\
\text { group and control group (systolic } \\
\text { BP } P=.038 \text {; diastolic BP } P=.005 \text {; } \\
\text { mean arterial BP } P=.006 \text {; heart } \\
\text { rate after exercise } P=.002 \text { ) }\end{array}$ \\
\hline $\begin{array}{l}\text { Rubinstein, } \\
2016 \text { [25] }\end{array}$ & $\begin{array}{l}\text { RCT for } 12 \\
\text { months; effective- } \\
\text { ness of preventive } \\
\text { mobile health inter- } \\
\text { vention in adults } \\
\text { with prehyperten- } \\
\text { sion }\end{array}$ & $\begin{array}{l}\text { Adults aged } 30-60 \\
\text { years with prehyperten- } \\
\text { sion from poor urban } \\
\text { settings in Argentina, } \\
\text { Guatemala, and Peru, } \\
\text { free of hypertension, } \\
\text { diabetes, and CVD; in- } \\
\text { tervention } n=316 \text {, usual } \\
\text { care } n=321\end{array}$ & $\begin{array}{l}\text { Intervention: monthly moti- } \\
\text { vational counselling calls } \\
\text { (healthy diet and PA) fol- } \\
\text { lowed by weekly text mes- } \\
\text { sages related to behavior } \\
\text { goals and readiness to } \\
\text { change; control: usual care }\end{array}$ & $\begin{array}{l}\text { Changes in BP, } \\
\text { weight, BMI, WC, } \\
\text { PA, diet }\end{array}$ & $\begin{array}{l}\text { Mean differences, baseline-adjust- } \\
\text { ed }(95 \% \mathrm{CI}) \text { : weight }-0.66 \mathrm{~kg} \\
(-1.24 \text { to }-0.07) \text {, BMI }-0.30 \\
\mathrm{~kg} / \mathrm{m}^{2}(-0.54 \text { to }-0.06) \text {, daily in- } \\
\text { take of high-sugar and -fat serv- } \\
\text { ings }-0.75(-1.30 \text { to }-0.20) \text {; } \\
\text { change in BP not significant }\end{array}$ \\
\hline
\end{tabular}

${ }^{\mathrm{a}} \mathrm{RCT}$ : randomized controlled trial.

${ }^{\mathrm{b}} \mathrm{PA}$ : physical activity.

${ }^{\mathrm{c}} \mathrm{BP}$ : blood pressure.

${ }^{\mathrm{d}} \mathrm{WC}$ : waist circumference. 
Table 3. Data extraction from type 2 diabetes mellitus (T2DM) studies.

\begin{tabular}{|c|c|c|c|c|c|}
\hline $\begin{array}{l}\text { First author, } \\
\text { date, reference }\end{array}$ & $\begin{array}{l}\text { Study design and } \\
\text { duration; objec- } \\
\text { tives }\end{array}$ & Study population & $\begin{array}{l}\text { Intervention and compara- } \\
\text { tor }\end{array}$ & Outcomes & Main results \\
\hline $\begin{array}{l}\text { Arens, } 2018 \\
{[26]}\end{array}$ & $\begin{array}{l}\text { Non-RCT } \mathrm{R}^{\mathrm{a}} \text { for } 12 \\
\text { months; effective- } \\
\text { ness of app-based } \\
\text { weight reduction } \\
\text { program for peo- } \\
\text { ple with metabol- } \\
\text { ic syndrome }\end{array}$ & $\begin{array}{l}\text { German adults aged } 30-65 \\
\text { years treated for metabolic } \\
\text { syndrome in } 23 \text { medical } \\
\text { practices; intervention } \\
n=148 \text {, usual care } n=85\end{array}$ & $\begin{array}{l}\text { Health goals regarding } \\
\text { weight and } \mathrm{PA}^{\text {b; }} \text { app for } \\
\text { feedback; physicians with } \\
\text { access to app data could } \\
\text { give feedback, initiate } \\
\text { messages, or modify goals; } \\
\leq 9 \text { free classes on diet and } \\
\text { PA; control: usual care }\end{array}$ & $\begin{array}{l}5 \% \text { weight reduction; } \\
\text { change in BMI }\end{array}$ & $\begin{array}{l}5 \% \text { weight reduction (adjust- } \\
\text { ed for time in study) ( } 95 \% \\
\mathrm{CI}): 44.8 \% \text { ( } 34.1 \text { to } 57.1 \text { ) in } \\
\text { intervention vs } 11.5 \% \text { ( } 4.6 \text { to } \\
27.0 \text { ) in control; Cox propor- } \\
\text { tional hazard model for time } \\
\text { to } 5 \% \text { weight reduction haz- } \\
\text { ard ratio } 6.2 \text { ( } 2.4 \text { to } 16.2 \text {; } \\
P<.001 \text { ), baseline adjusted } \\
\text { between groups change in } \\
\text { weight }(\mathrm{kg}) P=.06 \text { and BMI } \\
\left(\mathrm{kg} / \mathrm{m}^{2}\right) P=.10\end{array}$ \\
\hline
\end{tabular}

Bender, 2018 RCT for $3 \quad$ Filipino-American over- 5 in-person sessions, daily [27] months plus 3 months follow-up (no control for follow-up); effectiveness of mobile phone-based weight loss intervention to reduce T2DM risk

Block, 2015

[28]

Fischer, 2016 [29]

\section{RCT for 6} months plus 6 months follow-up (no control for follow-up); effectiveness of digital health intervention for T2DM risk reduction in prediabetics

RCT for 12 months; effectiveness of text message-supported T2DM prevention program

\section{weight or obese adults}

from United States at increased risk for T2DM,

able to walk $20 \mathrm{~min}$; intervention $n=33$, control $n=34$ step count via wearable device, daily food intake and weekly weight logged in app, weekly information on weight loss, PA, and diet via private Facebook page; control: waitlist

Prediabetics aged 30-69 years from United States with BMI $\geq 27 \mathrm{~kg} / \mathrm{m}^{2}$, without diabetes medication; intervention $n=163$, control $n=176$

Obese and overweight adults from United States without prediabetes, English or Spanish speaking; intervention $\mathrm{n}=82$, control $\mathrm{n}=81$
Tailored behavioral support for PA, diet, weight loss, stress, sleep; weekly emails with goals linked to website (tracking tools, coaching, social support, competition, health advice), app and automated phone calls; control: waitlist

6 text messages per week: skills, problem solving, motivation, stress reduction, recipes, web links to additional resources, PA promotion; weekly self-reported weight; eligible for individual motivational phone health coaching; control: usual care
Recruitment (goal $\mathrm{n}=50$ ), retention, $5 \%$ weight loss, changes in weight, $\mathrm{BMI}, \mathrm{WC}^{\mathrm{c}}$, $\mathrm{FBG}^{\mathrm{d}}, \mathrm{HbA}_{1 \mathrm{c}} \mathrm{e}^{\mathrm{C}}$

Weight loss $\geq 5 \%$ : intervention $36 \%$ vs control $6 \%$; betweengroup cross-level interaction (95\% CI): weight

$-1.1 \% /$ month $(-1.7$ to -0.53$)$ and $-0.85 \mathrm{~kg} /$ month $(-1.4$ to $-0.35)$, BMI $-0.93 \mathrm{~kg} / \mathrm{m}^{2}$ ( -1.5 to -0.40$), \mathrm{WC}-4.9 \mathrm{~cm}$ ( -7.5 to -2.6$)$, FBG -1.4 $\mathrm{mg} / \mathrm{dL}$ (-5.9 to 3.6$), \mathrm{HbA}_{1 \mathrm{c}}$ $-0.10 \%$ ( -0.21 to 0.002$)$

Decreased $\mathrm{HbA}_{1 \mathrm{c}}$, FBG, weight, BMI, $\mathrm{WC}$, triglyceride to $\mathrm{HDL}^{\mathrm{f}}$ ratio, metabolic syndrome, Framingham diabetes risk score

Mean $(95 \% \mathrm{CI}) \mathrm{HbA}_{1 \mathrm{c}}$ $-0.26 \%(-0.27$ to -0.24$)$ in intervention vs control $-0.18 \%$ ( -0.19 to -0.16$)$, FBG $-0.41 \mathrm{mmol} / \mathrm{L}$ ( -0.44 to, $-0.12)$ in intervention vs $-0.21 \mathrm{mmol} / \mathrm{L}(-0.15$ to $-0.10)$ in control, all outcomes significantly greater in intervention than control $(P<.001)$

Change in weight; percentage of participants with $\geq 3 \%$ or $5 \%$ weight loss, changes in $\mathrm{HbA}_{1 \mathrm{c}}$ and systolic $\mathrm{BP}^{\mathrm{g}}$, costs per participant

Weight $(95 \% \mathrm{CI})$ in intervention $-1.2 \mathrm{~kg}(-2.5$ to 0.1$)$ vs control $-0.3 \mathrm{~kg}(-1.2$ to 0.7$)$, $P=.05 ; 3 \%$ weight loss absolute difference between groups $17.0 \%, P=.02$; no significant difference for $5 \%$ weight loss; $\mathrm{HbA}^{1 \mathrm{c}}$ in intervention $-0.09 \%$ ( -0.2 to 0.0$)$ vs control $0.19 \%$ ( -0.1 to $0.5)$, systolic BP in intervention $0.35 \mathrm{mmHg}$ ( -2.8 to 3.5$)$ vs control $6.4 \mathrm{mmHg}$ (3.2 to 9.5)

Fukuoka, 2015 RCT for $5 \quad$ Overweight adults aged [30] months; effectiveness of mobile app-based intervention for T2DM prevention

\section{$\geq 35$ years from United}

States at high risk of diabetes; intervention $n=30$; control $n=31$ 2-week run-in period before randomizing; all daily step count via pedometer; intervention: mobile version of Diabetes Prevention Program, 6 in-person sessions, app: diaries for self-monitoring of weight, PA, and caloric intake, daily reminders and messages; control: pedometer only
$\%$ change in weight Weight $(95 \% \mathrm{CI})-6.8 \%$ and BMI; hip circum- $\quad(-12.2$ to -1.4$)$ in intervention ference, BP, lipid pro- vs $0.3 \%$ ( -2.7 to 3.3$)$ in confile, glucose levels, trol; BMI $-6.6 \%(-12.3$ to step count, PA, caloric -0.9$)$ in intervention vs $0.3 \%$ and fat intake $\quad(-2.7$ to 3.3$)$ in control; both $P<.001$; also significant differences in hip circumference, $\mathrm{BP}$, step count, and PA for intervention vs control; no effect on lipid profile, glucose levels, caloric or fat intake 


\begin{tabular}{|c|c|c|c|c|c|}
\hline $\begin{array}{l}\text { First author, } \\
\text { date, reference }\end{array}$ & $\begin{array}{l}\text { Study design and } \\
\text { duration; objec- } \\
\text { tives }\end{array}$ & Study population & $\begin{array}{l}\text { Intervention and compara- } \\
\text { tor }\end{array}$ & Outcomes & Main results \\
\hline
\end{tabular}

${ }^{\mathrm{a}} \mathrm{RCT}$ : randomized controlled trial.

${ }^{\mathrm{b}} \mathrm{PA}$ : physical activity.

${ }^{\mathrm{c}} \mathrm{WC}$ : waist circumference.

${ }^{\mathrm{d}}$ FBG: fasting blood glucose.

${ }^{\mathrm{e}} \mathrm{HbA}_{1 \mathrm{c}}$ : glycated hemoglobin.

${ }^{\mathrm{f}} \mathrm{HDL}$ : high-density lipoprotein.

${ }^{\mathrm{BP}}$ : blood pressure.

\section{Results of the Synthesis}

individually and in total. For each parameter, we provide a Summary

We synthesized the results of the data extraction according to the PICOS system. Table 4 summarizes CVD and T2DM data 
Table 4. Synthesis of findings.

\begin{tabular}{|c|c|c|c|c|c|}
\hline \multirow[t]{2}{*}{ Finding } & \multicolumn{2}{|c|}{ Cardiovascular disease } & \multicolumn{2}{|l|}{ Type 2 diabetes } & \multirow[t]{2}{*}{ Total (n) } \\
\hline & No. of studies & Reference & No. of studies & Reference & \\
\hline \multicolumn{6}{|l|}{ Target population } \\
\hline General population & 1 & {$[24]$} & $-^{\mathrm{a}}$ & - & 1 \\
\hline At risk of the disease & 2 & {$[23,25]$} & 6 & [26-31] & 8 \\
\hline \multicolumn{6}{|l|}{ Location } \\
\hline Spain & 1 & {$[24]$} & - & - & 1 \\
\hline United States & 1 & {$[23]$} & 4 & {$[27-30]$} & 5 \\
\hline Germany & - & - & 1 & {$[26]$} & 1 \\
\hline Latin America & 1 & {$[25]$} & - & - & 1 \\
\hline India & - & - & 1 & {$[31]$} & 1 \\
\hline \multicolumn{6}{|l|}{ Intervention delivery } \\
\hline SMS text messaging & 2 & {$[23,25]$} & 2 & {$[29,31]$} & 4 \\
\hline WhatsApp & 1 & {$[24]$} & - & - & 1 \\
\hline Mobile app & - & - & 4 & {$[26-28,30]$} & 4 \\
\hline \multicolumn{6}{|l|}{ Comparator } \\
\hline Usual care & 3 & [23-25] & 3 & {$[26,29,31]$} & 6 \\
\hline Waitlist & - & - & 2 & {$[27,28]$} & 2 \\
\hline Pedometer only & - & - & 1 & {$[30]$} & 1 \\
\hline Face-to-face training & 1 & {$[24]$} & - & - & 1 \\
\hline \multicolumn{6}{|l|}{ Outcomes $^{\text {b }}$} \\
\hline Weight loss & 1 & {$[25]$} & 3 & {$[27,28,30]$} & 4 \\
\hline Reduced BMI & 1 & {$[25]$} & 3 & {$[27,28,30]$} & 4 \\
\hline Reduced waist circumference & - & - & 2 & {$[27,28]$} & 2 \\
\hline $\begin{array}{l}\text { Lower fasting blood glucose/glycated } \\
\text { hemoglobin }\end{array}$ & $\mathrm{N} / \mathrm{A}^{\mathrm{c}}$ & - & 1 & {$[28]$} & 1 \\
\hline Improved diet & 2 & {$[23,25]$} & 1 & {$[31]$} & 3 \\
\hline Improved physical activity & - & - & 2 & {$[30,31]$} & 2 \\
\hline Improved blood pressure & - & - & 1 & {$[30]$} & 1 \\
\hline \multicolumn{6}{|l|}{ Study design } \\
\hline Randomized controlled trial & 1 & {$[25]$} & 5 & {$[27-31]$} & 6 \\
\hline Nonrandomized controlled trial & 2 & {$[23,24]$} & 1 & [26] & 3 \\
\hline
\end{tabular}

a__: data not available.

${ }^{\mathrm{b}}$ Statistically significant compared with control group.

${ }^{\mathrm{c}} \mathrm{N} / \mathrm{A}$ : not applicable.

\section{Participants}

The CVD studies were conducted in Spain, the United States, and Latin America. For the T2DM studies, 1 was conducted in Germany, 1 in India, and 4 in the United States. All studies had small to medium samples, ranging from 32 to 637 participants. For CVD, 2 of the 3 studies targeted populations at higher risk of developing CVD [23,25], whereas the study by Muntaner-Mas et al [24] included healthy people. For T2DM, all studies focused on populations at increased risk of the disease.

\section{Interventions}

The duration of the interventions varied from 10 weeks to 2 years. In 4 studies the participants received text messages $[23,25,29,31]$, in 1 study the intervention was delivered via WhatsApp [24], and in the remaining 4 studies a specifically developed mobile phone app was involved [26-28,30]. Only 1 intervention was delivered fully automated [28]; all other interventions included human involvement [23-27,29-31]. 


\section{Comparators}

Of the studies, 6 used usual care as the control group. In 1 trial, the control group received pedometers only [30]; 1 study had a second comparator group, additional to usual care, which received face-to-face training sessions [24]; and 2 studies used waitlist controls $[27,28]$, meaning that the control group received the intervention after the intervention group had completed it.

\section{Outcomes}

The mobile phone interventions led to statistically significant weight loss compared with the control group in 4 studies $[25,27,28,30]$, ranging from a difference of $-0.66 \mathrm{~kg}(P=.04)$ over 12 months [25] to $-6.2 \mathrm{~kg}$ for the intervention compared with $0.3 \mathrm{~kg}$ for the control group $(P<.001)$ over 5 months [30]. The same studies reported a statistically significant decrease in BMI compared with the control group [25,27,28,30], ranging from a difference of $-0.3 \mathrm{~kg} / \mathrm{m}^{2}(P=.02)$ over 12 months [25] to $-2.2 \mathrm{~kg} / \mathrm{m}^{2}$ for the intervention compared with $0.1 \mathrm{~kg} / \mathrm{m}^{2}$ for the control group $(P<.001)$ over 5 months [30]. A smaller waist circumference due to the intervention was measured in 2 T2DM studies [27,28], from $-4.56 \mathrm{~cm}$ for the intervention compared with $-2.22 \mathrm{~cm}(P<.001)$ for the control group over 6 months [28] to a cross-level interaction of $-4.9 \mathrm{~cm}(95 \% \mathrm{CI}-7.5$ to -2.6) over 3 months [27]. One T2DM study reported statistically significantly lower fasting blood glucose $(-0.41 \mathrm{mmol} / \mathrm{L}$ in the intervention compared with $-0.12 \mathrm{mmol} / \mathrm{L}$ in the control group; $P<.001)$ and glycated hemoglobin levels $(-0.26 \%$ in the intervention compared with $-0.18 \%$ in the control group; $P<.001)$ over 6 months [28]. Statistically significantly greater changes in the lipid profile were observed in the intervention group than in the control group in 2 of the T2DM trials [28,31], from a difference in mean change of high-density lipoprotein cholesterol of $0.033 \mathrm{mmol} / \mathrm{L}$ (95\% CI 0.011 to 0.054$)$ and triglycerides of $-0.080 \mathrm{mmol} / \mathrm{L}(95 \% \mathrm{CI}-0.17$ to -0.06$)$ over
2 years [31] to a triglyceride to high-density lipoprotein ratio of -0.21 in the intervention compared with 0.21 in the control group $(P=.04)$ over 6 months [28]. Improved diet patterns that were statistically superior to the control group were observed in 3 studies [23,25,31], of which 2 studies aimed at CVD prevention. Improvements in physical activity were reported in 2 T2DM studies [30,31]. Blood pressure was statistically significantly improved in the intervention groups compared with the control group in 1 T2DM study [30].

\section{Study Design}

A total of 6 studies were RCTs [25,27-31]; the remaining 3 were non-RCTs [23,24,26].

\section{Results of Literature Quality Assessment}

All RCTs used acceptable methods for randomization [25,27-31], but in none of the studies were the participants blinded to the design, which is an inherent problem with this type of intervention. Figure 3 summarizes the risk of bias for the RCTs. Of the 6 studies, 3 ensured blinding of the study personnel $[25,27,28]$ and 3 ensured the blinding of the outcome assessors [25,28,31]. Apart from the study by Fukuoka et al [30], all RCTs published study protocols on the ClinicalTrials.gov database. Overall, due to performance bias, all studies were at high risk of bias.

Of the 3 non-RCTs $[23,24,26]$, the study by Muntaner-Mas et al [24] was at moderate risk of bias, the study by Gore et al [23] was at high risk of bias, and the study by Arens et al [26] was at critical risk of bias. Figure 4 summarizes the risk of bias for the non-RCTs. The biggest issue with the study by Arens et al [26] was that missing data were not handled adequately, putting the study at critical risk of bias. We assessed the study by Gore et al [23] to be at high risk of confounding because some of the measurements that were used to control for confounding were based on nonvalidated questionnaires. 
Figure 3. Risk-of-bias summary table for the randomized controlled trials. The upper 1 is a cardiovascular disease study and the remainder are type 2 diabetes studies.

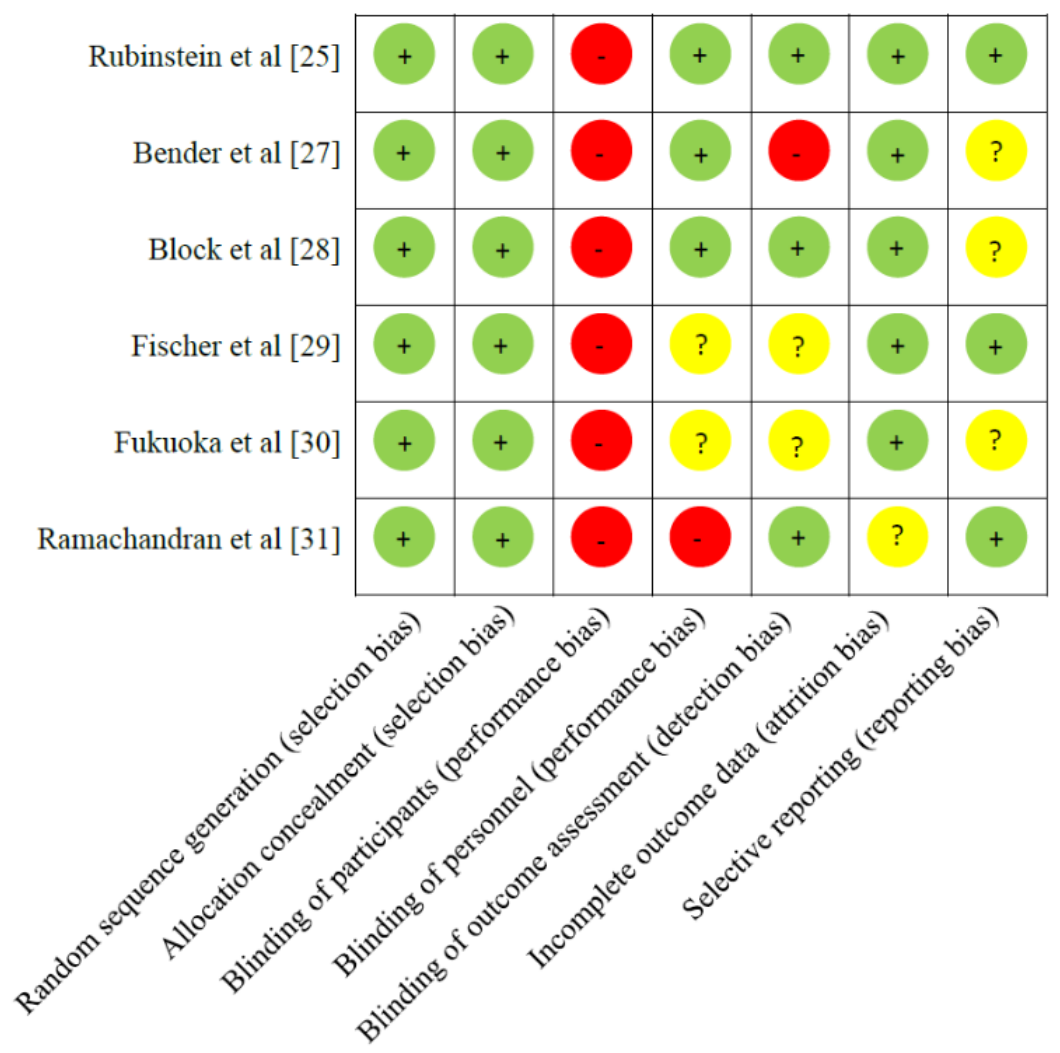

Legend: + low risk of bias, - serious risk of bias, ? unclear.

Figure 4. Risk-of-bias summary table for the nonrandomized controlled trials. The upper 2 are cardiovascular disease studies and the lower 1 is a type 2 diabetes study.

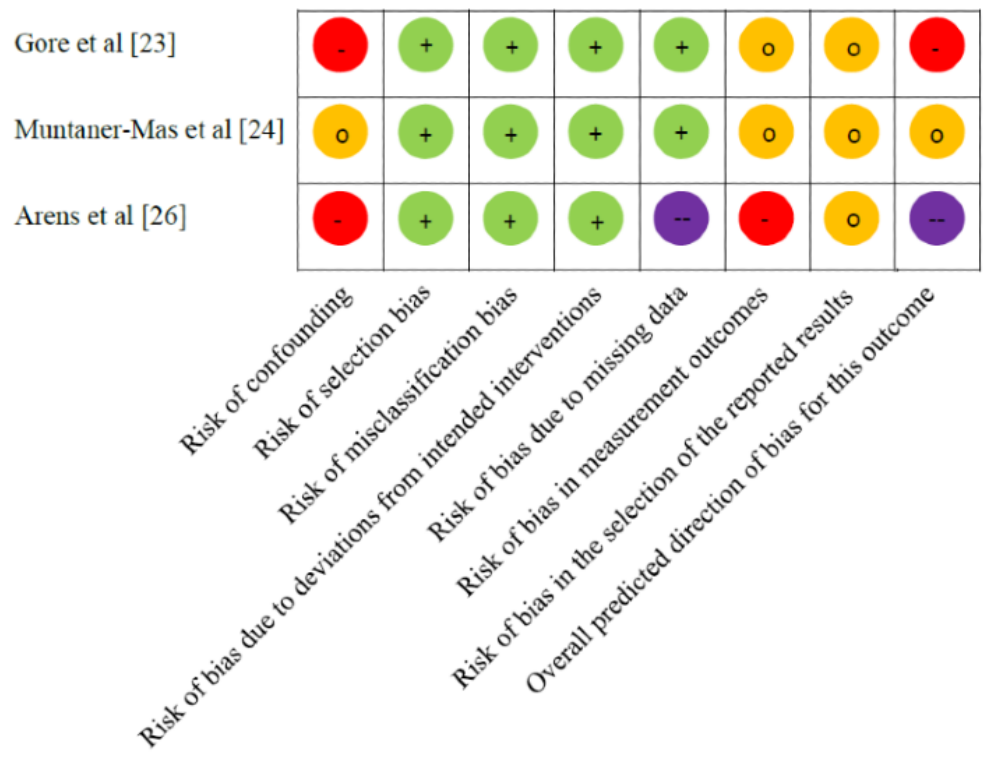

Legend: + low risk of bias, 0 moderate risk of bias, - serious risk of bias,

- critical risk of bias. 


\section{Discussion}

\section{Principal Findings}

We identified only a small number $(n=9)$ of articles that fulfilled the preset inclusion and exclusion criteria. We assessed most of the studies to be at high risk of bias. Additionally, 3 studies were underpowered (sample size <100), and 2 studies had short follow-up times ( $<6$ months). Ideally, to show the effectiveness in reducing the risk of CVD or T2DM, the studies should have reported disease incidence rates. The only study that did this was that by Ramachandran et al [31], with their primary outcome being a decrease of T2DM incidence due to the SMS text messaging intervention over 2 years. Block et al [28] reported the percentage of people with metabolic syndrome as defined by the International Diabetes Federation Task Force on Epidemiology and Prevention [32]. Block et al [28] also measured change in the Framingham 8-year diabetes risk score [33], and Gore et al [23] measured change in the Framingham 10-year CVD risk score [20]. All other studies reported single risk factors rather than multivariable absolute risk of disease. None of the identified studies directly targeted tobacco smoking cessation or responsible alcohol intake. Rubinstein et al [25] mentioned in their article that their original protocol included both lifestyle factors, but they were later excluded. According to the authors, alcohol intake was considered a sensitive matter requiring face-to-face interactions, while tobacco smoking was excluded because supposedly, compared with physical activity and diet, it had less effect on the onset of hypertension and was more difficult to target via a mobile health intervention [25]. Overall, there were some positive findings suggesting that mobile health-based interventions can achieve at least small to moderate reductions in CVD and T2DM risk, although these were based on weak evidence.

\section{Strengths and Limitations}

The strength of this literature review was that it followed the PRISMA statement. We systematically searched several databases to identify all relevant published articles. Further, we conducted a manual search through the snowballing technique. For the title and abstract screening, a 10\% random sample of all retrieved articles was validated by a second researcher, and 2 reviewers independently performed the full article selection. However, only 1 researcher conducted the database search, the data extraction, and the risk-of-bias assessment. Although we a priori restricted the search to English- and German-language articles, we did not exclude any articles because they were not available in these 2 languages. We did not perform a meta-analysis due to the small number of publications that met the inclusion criteria and the differences in their interventions and outcome measures.

\section{Comparison With Prior Work}

Previous mobile health research has focused more on self-management of chronic diseases than on prevention. In their systematic review and meta-analysis, Wu et al [34] investigated the effectiveness of mobile phone apps for diabetes self-management (including prediabetes, gestational diabetes, type 1 diabetes, and T2DM). They identified 3 studies that targeted prediabetes, 2 of which we also included in this review.
The overall conclusion of $\mathrm{Wu}$ et al [34] was that there was evidence for the effectiveness of app interventions in T2DM self-management, but not for prediabetes. Lunde et al [35] conducted a systematic review looking at various types of noncommunicable diseases and lifestyle advice. Most of the identified studies (8 out of 9) targeted T2DM patients for whom the authors measured improvements in lifestyle factors, particularly reduced glycated hemoglobin levels (in 5 of the 8 studies). For CVD patients, Lunde et al [35] found only 2 relevant articles, and these were without statistically significant improvements in any of the outcomes of interest (weight, BMI, waist circumference, physical activity, and quality of life). A systematic review by Coorey et al [36] focused on self-management of CVD via mobile apps, in which they concluded that short-term improvements in behavior and risk factors were possible but there was insufficient evidence for long-term effects. Alessa et al [37] reported from their systematic review of 21 studies that mobile apps could reduce blood pressure, although the evidence originated mainly from studies that had a high risk of bias.

Palmer et al [14] conducted a systematic review of noncommunicable disease prevention through smoking cessation, alcohol reduction, physical activity, and diet using mobile technology. In total, they found 71 articles, but only 2 of the studies were aimed at the combination of physical activity, diet, and smoking cessation, with both studies targeting secondary prevention of CVD. Among the studies they reviewed, 8 RCTs focused on alcohol reduction but did not include any other lifestyle advice, with these studies specifically targeting heavy drinkers [14]. In general, it appears that many interventions are designed to provide advice for 1 or 2 behavioral risk factors that are associated with increased chronic disease risk, whereas there were only a few evaluation studies of comprehensive mobile health interventions addressing the 4 common behavioral risk factors (ie, tobacco smoking, excessive alcohol consumption, physical inactivity, and poor diet) [14]. Noble et al [13] stated in their systematic review that there were clustering patterns between the 4 behavioral risk factors-tobacco smoking, excessive alcohol consumption, physical inactivity, and poor diet—which indicated similar or the same reasons causing these behaviors. Hence, the authors suggested that future interventions should apply a holistic approach instead of targeting single risk factors. Similarly, Geller et al [38] called for future research studies to focus on improved lifestyles, meaning a change in multiple health behaviors rather than 1 , even if it might be harder to achieve. Meader et al [39] reported in their systematic review that targeting smoking simultaneously with other behaviors resulted in negative outcomes for diet and physical activity, suggesting that it might be more beneficial to apply a sequential approach. In a Cochrane review published in 2016, Whittaker et al [40] stated that studies have demonstrated that mobile phone-based interventions can be effective in achieving smoking cessation over 6 months, particularly SMS text messaging in high-income countries.

\section{Implications and Future Directions}

Most studies that were conducted according to the review's inclusion criteria were at high risk of bias. This review only 
considered studies of multirisk factor interventions, which resulted in only 9 studies being included. There is a lack of research evaluating interventions that address the 4 common behavioral risk factors (ie, tobacco smoking, excessive alcohol consumption, physical inactivity, and poor diet) in a single mobile health intervention. Researchers may have preferred to focus on 1 risk factor at a time due to simplicity for participants and clarity of intervention-outcome relationships. Hence, future studies should further explore the use of mobile technology for primary disease prevention, by applying a rigorous study design.

\section{Conclusions}

According to the findings of this systematic review, evidence for the effectiveness of mobile health-based interventions in reducing the risk of CVD and T2DM is scarce due to the quality of the included studies and the small effects that were measured. This highlights the need for further high-quality research to investigate the potential of mobile health interventions.

\section{Acknowledgments}

This research was supported by a joint stipend from the University of New South Wales and the Commonwealth Scientific and Industrial Research Organisation.

\section{Authors' Contributions}

VHB participated in research design, data collection, data analysis, and writing of the manuscript. SL participated in data collection, data analysis, and revision of the manuscript. MV, MB, and $\mathrm{MH}$ contributed to research design, data collection, data analysis, and revision of the manuscript. All authors provided final approval of the version to be published.

\section{Conflicts of Interest}

None declared.

\section{Multimedia Appendix 1}

Search strategy.

[DOC File, 48 KB-Multimedia Appendix 1]

\section{References}

1. GBD 2017 Causes of Death Collaborators. Global, regional, and national age-sex-specific mortality for 282 causes of death in 195 countries and territories, 1980-2017: a systematic analysis for the Global Burden of Disease Study 2017. Lancet 2018 Nov 10;392(10159):1736-1788 [FREE Full text] [doi: 10.1016/S0140-6736(18)32203-7] [Medline: $\underline{30496103]}$

2. GBD 2017 Disease and Injury Incidence and Prevalence Collaborators. Global, regional, and national incidence, prevalence, and years lived with disability for 354 diseases and injuries for 195 countries and territories, 1990-2017: a systematic analysis for the Global Burden of Disease Study 2017. Lancet 2018 Dec 10;392(10159):1789-1858 [FREE Full text] [doi: 10.1016/S0140-6736(18)32279-7] [Medline: 30496104]

3. GBD 2017 Risk Factor Collaborators. Global, regional, and national comparative risk assessment of 84 behavioural, environmental and occupational, and metabolic risks or clusters of risks for 195 countries and territories, 1990-2017: a systematic analysis for the Global Burden of Disease Study 2017. Lancet 2018 Nov 10;392(10159):1923-1994 [FREE Full text] [doi: 10.1016/S0140-6736(18)32225-6] [Medline: 30496105]

4. Gellert C, Schöttker B, Brenner H. Smoking and all-cause mortality in older people: systematic review and meta-analysis. Arch Intern Med 2012 Jun 11;172(11):837-844. [doi: 10.1001/archinternmed.2012.1397] [Medline: 22688992]

5. Wood AM, Kaptoge S, Butterworth AS, Willeit P, Warnakula S, Bolton T, Emerging Risk Factors Collaboration/EPIC-CVD/UK Biobank Alcohol Study Group. Risk thresholds for alcohol consumption: combined analysis of individual-participant data for 599912 current drinkers in 83 prospective studies. Lancet 2018 Dec 14;391(10129):1513-1523. [doi: 10.1016/S0140-6736(18)30134-X] [Medline: 29676281]

6. Chudasama YV, Khunti KK, Zaccardi F, Rowlands AV, Yates T, Gillies CL, et al. Physical activity, multimorbidity, and life expectancy: a UK Biobank longitudinal study. BMC Med 2019 Jun 12;17(1):108 [FREE Full text] [doi: 10.1186/s12916-019-1339-0] [Medline: 31186007]

7. Zhang B, Zhao Q, Guo W, Bao W, Wang X. Association of whole grain intake with all-cause, cardiovascular, and cancer mortality: a systematic review and dose-response meta-analysis from prospective cohort studies. Eur J Clin Nutr 2018 Dec;72(1):57-65. [doi: 10.1038/ejcn.2017.149] [Medline: 29091078]

8. World Health Organization. Global action plan for the prevention and control of noncommunicable diseases $2013-2020$. Geneva, Switzerland: World Health Organization; 2013. URL: https://apps.who.int/iris/bitstream/handle/10665/94384/ 9789241506236 eng.pdfjsessionid=75D5722BE3A73FAE254F414C58825563?sequence $=1$ [accessed 2019-12-19]

9. World Health Organization. WHO guideline recommendations on digital interventions for health system strengthening. Geneva, Switzerland: World Health Organization; 2019. URL: https://apps.who.int/iris/bitstream/handle/10665/311941/ 9789241550505-eng.pdf?ua=1 [accessed 2019-12-19] 
10. Wilson K. Mobile cell phone technology puts the future of health care in our hands. CMAJ 2018 Apr 03;190(13):E378-E379. [doi: 10.1503/cmaj.180269] [Medline: 29615420]

11. Taylor K, Silver L. Smartphone ownership is growing rapidly around the world, but not always equally. Washington, DC: Pew Research Center; 2019 Feb 05. URL: https://www.pewresearch.org/global/2019/02/05/ smartphone-ownership-is-growing-rapidly-around-the-world-but-not-always-equally/ [accessed 2019-10-12]

12. Riley WT, Rivera DE, Atienza AA, Nilsen W, Allison SM, Mermelstein R. Health behavior models in the age of mobile interventions: are our theories up to the task? Transl Behav Med 2011 Mar;1(1):53-71 [FREE Full text] [doi: 10.1007/s13142-011-0021-7] [Medline: 21796270]

13. Noble N, Paul C, Turon H, Oldmeadow C. Which modifiable health risk behaviours are related? A systematic review of the clustering of Smoking, Nutrition, Alcohol and Physical activity ('SNAP') health risk factors. Prev Med 2015 Dec;81:16-41. [doi: 10.1016/j.ypmed.2015.07.003] [Medline: 26190368]

14. Palmer M, Sutherland J, Barnard S, Wynne A, Rezel E, Doel A, et al. The effectiveness of smoking cessation, physical activity/diet and alcohol reduction interventions delivered by mobile phones for the prevention of non-communicable diseases: a systematic review of randomised controlled trials. PLoS One 2018;13(1):e0189801 [FREE Full text] [doi: 10.1371/journal.pone.0189801] [Medline: 29304148]

15. Moher D, Liberati A, Tetzlaff J, Altman DG. Preferred reporting items for systematic reviews and meta-analyses: the PRISMA statement. Ann Intern Med 2009 Aug 18;151(4):264-9, W64. [Medline: 19622511]

16. Lefebvre C, Manheimer E, Glanville J. Boolean operators (AND, OR and NOT). In: Higgins JPT, Green S, editors. Cochrane Handbook for Systematic Reviews of Interventions. Oxford, UK: Cochrane Collaboration; 2011. URL: https://handbook-5-1. cochrane.org/index.htm\#chapter 6/6 47 boolean operators and or and not.htm [accessed 2019-09-26]

17. Greenhalgh T, Peacock R. Effectiveness and efficiency of search methods in systematic reviews of complex evidence: audit of primary sources. BMJ 2005 Nov 05;331(7524):1064-1065 [FREE Full text] [doi: 10.1136/bmj.38636.593461.68] [Medline: 16230312$]$

18. World Health Organization. Cardiovascular disease. Geneva, Switzerland: WHO; 2019. URL: https://www.who.int/ cardiovascular_diseases/about_cvd/en/ [accessed 2019-06-19]

19. World Health Organization. Diabetes. Geneva, Switzerland: WHO; 2018 Oct 30. URL: https://www.who.int/news-room/ fact-sheets/detail/diabetes [accessed 2019-12-16]

20. D'Agostino RB, Vasan RS, Pencina MJ, Wolf PA, Cobain M, Massaro JM, et al. General cardiovascular risk profile for use in primary care: the Framingham Heart Study. Circulation 2008 Feb 12;117(6):743-753. [doi:

10.1161/CIRCULATIONAHA.107.699579] [Medline: 18212285 ]

21. Cochrane Collaboration. The Cochrane Collaboration's tool for assessing risk of bias: 8.5.1 Overview. In: Higgins JPT, Green S, editors. Cochrane Handbook for Systematic Reviews of Interventions. Oxford, UK: Cochrane Collaboration; 2011. URL: https://handbook-5-1.cochrane.org/index.htm\#chapter 8/8 51 overview.htm [accessed 2019-10-24]

22. Sterne JA, Hernán MA, Reeves BC, Savović J, Berkman ND, Viswanathan M, et al. ROBINS-I: a tool for assessing risk of bias in non-randomised studies of interventions. BMJ 2016 Oct 12;355:i4919. [Medline: 27733354]

23. Gore MO, Krantz MJ, Albright K, Beaty B, Coronel-Mockler S, Bull S, et al. A controlled trial of mobile short message service among participants in a rural cardiovascular disease prevention program. Prev Med Rep 2019 Mar;13:126-131 [FREE Full text] [doi: 10.1016/j.pmedr.2018.11.021] [Medline: 30568871]

24. Muntaner-Mas A, Vidal-Conti J, Borràs PA, Ortega FB, Palou P. Effects of a Whatsapp-delivered physical activity intervention to enhance health-related physical fitness components and cardiovascular disease risk factors in older adults. J Sports Med Phys Fitness 2017;57(1-2):90-102. [doi: 10.23736/S0022-4707.16.05918-1] [Medline: 26364690]

25. Rubinstein A, Miranda JJ, Beratarrechea A, Diez-Canseco F, Kanter R, Gutierrez L, et al. Effectiveness of an mHealth intervention to improve the cardiometabolic profile of people with prehypertension in low-resource urban settings in Latin America: a randomised controlled trial. Lancet Diabetes Endocrinol 2016 Jan;4(1):52-63. [doi:

10.1016/S2213-8587(15)00381-2] [Medline: 26653067]

26. Arens JH, Hauth W, Weissmann J. Novel app- and web-supported diabetes prevention program to promote weight reduction, physical activity, and a healthier lifestyle: observation of the clinical application. J Diabetes Sci Technol 2018 Jul;12(4):831-838 [FREE Full text] [doi: 10.1177/1932296818768621] [Medline: 29584454]

27. Bender MS, Cooper BA, Flowers E, Ma R, Arai S. Filipinos Fit and Trim - a feasible and efficacious DPP-based intervention trial. Contemp Clin Trials Commun 2018 Dec;12:76-84 [FREE Full text] [doi: 10.1016/j.conctc.2018.09.004] [Medline: 30294699]

28. Block G, Azar KM, Romanelli RJ, Block TJ, Hopkins D, Carpenter HA, et al. Diabetes prevention and weight loss with a fully automated behavioral intervention by email, web, and mobile phone: a randomized controlled trial among persons with prediabetes. J Med Internet Res 2015 Oct 23;17(10):e240 [FREE Full text] [doi: 10.2196/jmir.4897] [Medline: 26499966]

29. Fischer HH, Fischer IP, Pereira RI, Furniss AL, Rozwadowski JM, Moore SL, et al. Text message support for weight loss in patients with prediabetes: a randomized clinical trial. Diabetes Care 2016 Dec;39(8):1364-1370. [doi: 10.2337/dc15-2137] [Medline: 26861922] 
30. Fukuoka Y, Gay CL, Joiner KL, Vittinghoff E. A novel diabetes prevention intervention using a mobile app: a randomized controlled trial with overweight adults at risk. Am J Prev Med 2015 Aug;49(2):223-237 [FREE Full text] [doi: 10.1016/j.amepre.2015.01.003] [Medline: 26033349]

31. Ramachandran A, Snehalatha C, Ram J, Selvam S, Simon M, Nanditha A, et al. Effectiveness of mobile phone messaging in prevention of type 2 diabetes by lifestyle modification in men in India: a prospective, parallel-group, randomised controlled trial. Lancet Diabetes Endocrinol 2013 Nov;1(3):191-198. [doi: 10.1016/S2213-8587(13)70067-6] [Medline: 24622367]

32. Alberti KGMM, Eckel RH, Grundy SM, Zimmet PZ, Cleeman JI, Donato KA, International Diabetes Federation Task Force on Epidemiology and Prevention, National Heart, Lung, and Blood Institute; American Heart Association, American Heart Association, World Heart Federation, International Atherosclerosis Society, International Association for the Study of Obesity. Harmonizing the metabolic syndrome: a joint interim statement of the International Diabetes Federation Task Force on Epidemiology and Prevention; National Heart, Lung, and Blood Institute; American Heart Association; World Heart Federation; International Atherosclerosis Society; and International Association for the Study of Obesity. Circulation 2009 Oct 20;120(16):1640-1645. [doi: 10.1161/CIRCULATIONAHA.109.192644] [Medline: 19805654]

33. Wilson PWF, Meigs JB, Sullivan L, Fox CS, Nathan DM, D'Agostino RB. Prediction of incident diabetes mellitus in middle-aged adults: the Framingham Offspring Study. Arch Intern Med 2007 May 28;167(10):1068-1074. [doi: 10.1001/archinte.167.10.1068] [Medline: 17533210 ]

34. Wu X, Guo X, Zhang Z. The efficacy of mobile phone apps for lifestyle modification in diabetes: systematic review and meta-analysis. JMIR Mhealth Uhealth 2019 Jan 15;7(1):e12297 [FREE Full text] [doi: 10.2196/12297] [Medline: 30664494]

35. Lunde P, Nilsson BB, Bergland A, Kværner KJ, Bye A. The effectiveness of smartphone apps for lifestyle improvement in noncommunicable diseases: systematic review and meta-analyses. J Med Internet Res 2018 May 04;20(5):e162 [FREE Full text] [doi: 10.2196/jmir.9751] [Medline: 29728346]

36. Coorey GM, Neubeck L, Mulley J, Redfern J. Effectiveness, acceptability and usefulness of mobile applications for cardiovascular disease self-management: systematic review with meta-synthesis of quantitative and qualitative data. Eur $\mathbf{J}$ Prev Cardiol 2018 Mar;25(5):505-521. [doi: 10.1177/2047487317750913] [Medline: 29313363]

37. Alessa T, Abdi S, Hawley MS, de Witte L. Mobile apps to support the self-management of hypertension: systematic review of effectiveness, usability, and user satisfaction. JMIR Mhealth Uhealth 2018 Jul 23;6(7):e10723 [FREE Full text] [doi: 10.2196/10723] [Medline: 30037787]

38. Geller K, Lippke S, Nigg CR. Future directions of multiple behavior change research. J Behav Med 2017 Feb;40(1):194-202. [doi: 10.1007/s10865-016-9809-8] [Medline: 27785652]

39. Meader N, King K, Wright K, Graham HM, Petticrew M, Power C, et al. Multiple risk behavior interventions: meta-analyses of RCTs. Am J Prev Med 2017 Jul;53(1):e19-e30 [FREE Full text] [doi: 10.1016/j.amepre.2017.01.032] [Medline: 28258777]

40. Whittaker R, McRobbie H, Bullen C, Rodgers A, Gu Y. Mobile phone-based interventions for smoking cessation. Cochrane Database Syst Rev 2016;4:CD006611. [doi: 10.1002/14651858.CD006611.pub4] [Medline: 27060875]

\section{Abbreviations}

CVD: cardiovascular disease

PRISMA: Preferred Reporting Items for Systematic Reviews and Meta-Analyses

PROSPERO: International Prospective Register of Systematic Reviews

RCT: randomized controlled trial

T2DM: type 2 diabetes mellitus

WHO: World Health Organization

Edited by G Eysenbach; submitted 06.06.20; peer-reviewed by C Hockham, V Haldane; comments to author 25.06.20; revised version
received 10.08.20; accepted 02.09.20; published 29.10.20
Please cite as:
Buss VH, Leesong S, Barr M, Varnfield M, Harris $M$
Primary Prevention of Cardiovascular Disease and Type 2 Diabetes Mellitus Using Mobile Health Technology: Systematic Review
of the Literature
J Med Internet Res 2020;22(10):e21159
URL: $\underline{\text { http://www.jmir.org/2020/10/e21159/ }}$
doi: $\underline{10.2196 / 21159}$
PMID: $\underline{3118936}$

(C) Vera Helen Buss, Stuart Leesong, Margo Barr, Marlien Varnfield, Mark Harris. Originally published in the Journal of Medical Internet Research (http://www.jmir.org), 29.10.2020. This is an open-access article distributed under the terms of the Creative 
Commons Attribution License (https://creativecommons.org/licenses/by/4.0/), which permits unrestricted use, distribution, and reproduction in any medium, provided the original work, first published in the Journal of Medical Internet Research, is properly cited. The complete bibliographic information, a link to the original publication on http://www.jmir.org/, as well as this copyright and license information must be included. 